\title{
Multi-criterion parameters optimization of the heat exchanger element air heating system of a building
}

\author{
Andrei Melekhin \\ Moscow State University of Civil Engineering, Yaroslavskoe shosse, 26, Moscow, 129337, Russia
}

\begin{abstract}
Air heating systems of buildings are resource-consuming systems, for this reason, improving their resource efficiency appears to be of great significance. The author have developed a mathematical model of process of heat exchange in heat exchange surfaces of apparatuses with the solution of multicriteria optimization problem, an optimal range of managed parameters influencing the process of heat exchange with minimal metal consumption and the maximum heat output fin heat exchanger, the regularities of heat exchange process with getting generalizing dependencies distribution of temperature on the heat-release surface of the heat exchanger engineering systems of buildings, defined convergence of the results of research in the calculation on the basis of theoretical dependencies and solving mathematical model. Finding the best managed of the parameters of the heat exchanger element air heating system of a building is possible with the developed by the author of a comprehensive method of research based on multi-criteria parameters optimization with the introduction of empirically obtained data.
\end{abstract}

\section{Introduction}

The conduct of practical studies to optimize basic parameters in engineering systems of buildings is urged by power-saving requirements.

The given practical problem of improving engineering systems is to optimize the design of the heat exchanger in air heating systems of buildings.

Air heating systems of buildings are resource-consuming systems, for this reason, improving their resource efficiency appears to be of great significance.

Heating of air is provided by heat exchangers, which have been studied quite thoroughly. The studies involved different authors to deal with particular aspects of improving heat exchange elements [13].

The main properties of heat exchangers, such as amount of heat exchange, area of heat exchange, metal capacity and cost of an apparatus depend largely on the size of ribbing, so the efficiency of the design is determined by the optimal height of the rib [11,12].

One of the authors of this paper V.M. Khrustalev looked into the criterion to assess the efficiency of heat exchanger design. The paper also suggests theoretical dependencies to 
calculate technical characteristics of heat exchangers. However, these dependencies do not allow optimization on several parameters $[4,5,6]$.

A.A. Melekhin in his previous papers studied the multi-criterion optimization of the rib in heat exchangers based on two criteria, however, other parameters were not considered [1]. In the given paper the author makes a thermodynamic analysis and optimizes heat exchangers of air-cooling, at the same time these improvements are not based on the complex approach [8].

The occurrence of new methods, namely a complex method, allows combining mathematical modeling with visualization of heat fields, and as a result, obtaining optimal parameters of heat exchangers for the given systems.

The purpose of the given study is improving the efficiency of heat exchangers by optimizing their parameters and design.

\section{Materials/methods}

In order to set optimal parameters for the heat exchanger and balance its design with technological elements the author conducted actual studies with the help of the complex method. It comprises optimization of parameters for heat exchanging process based on multi-criterion multi-parameter mathematical models and experiments with thermal fields visualization.

The aim of the study is to increase the efficiency of engineering systems of buildings by optimization the parameters of the elements of heat exchangers used in air heating systems of buildings.

To achieve this goal we set and solved the following tasks:

- we have developed a mathematical model of multi-criterion problem to optimize heat exchange on the ribbed heat exchanging surfaces.

- using the mathematical model we developed, we have determined the mechanism of heat exchanging process and have derived dependencies of temperature distribution on heat exchange surfaces in heating systems of buildings during the heating season;

- we have made a comparison of the obtained results with the results based on the established theoretical dependencies;

- we have reduced the metal capacity of the heat exchanger by improving its heat engineering characteristics.

The novelty of the given paper lies in the following:

- we have elaborated a new complex research technique, based on multi-criterion problems with generic dependencies, obtained from empirical data.

- we have obtained functional dependence of process parameters on heat exchanging surfaces on optimal geometrical parameters of the heat exchanger.

The practical value of the paper is in the following:

- we have derived semi-empirical equations for computing and designing air heating systems in buildings;

- we have reduced metal capacity of heat exchangers which are used in air heating systems of buildings.

To achieve this goal the author posed and solved the following tasks: - developed a mathematical model of multi criteria optimization problems of the process of heat transfer on finned heat transfer surfaces of the apparatus;

- the regularities of process of heat exchange with the receipt of the generalized dependency of the temperature distribution on the heat-transfer surface of heat exchanger air heating systems of the buildings at work during the heating period using the developed mathematical model; 
- a comparison of the obtained results with the known theoretical dependencies; - reduced metal heat exchanger optimized thermal performance.

The optimization problems are solved using the method of non-linear optimization in computing complex IOZO NM 3.0b [7].

Besides, the solution of such problems is also possible with the help of non-linear optimization program Generalized Reduced Gradient (GRG2), designed by Leon Lasdon, University of Texas at Austin and Allan Waren, Cleveland State University, and based on the method of conjugate gradients - iterative method for unconstrained optimization in multidimensional space. The main advantage of this software package is that it is able to solve the quadric optimization problem within finite number of moves. So, first the author describes the method of conjugate gradients to optimize the quadric functional, then he derives iterative formulas and estimates convergence rate. Next, the author demonstrates, how the method of conjugate gradients is generalized to optimize arbitrary functional, looks at different variations of the method, assesses convergence. The shortcoming is that controllable and non-controllable parameters and criteria are constrained [9].

It is possible to use as a mathematical model a two-criterion problem of optimization with fuzzy constraints. The fuzzy constraints can be set by specific preference functions. The solution is made in Boolean variables with the help of stochastic search, improved by heuristics. The algorithm is implemented in the form of a universal software module [10].

Solution of multi-criterion multi-parameter non-linear optimization problem of engineering systems in buildings suggested applying software package IOSO NM version 3.0b, where the author entered empirical data from thermal imaging. A special feature of this software is its compatibility with Microsoft Excel and other programs. IOSO package allows setting controllable and non-controllable parameters, optimal criteria, and constraints for the process. Further, IOSO program establishes optimal process parameters by using the data from Excel.

Preliminary IOSO procedure is forming the initial experiment plan, which can be passive (using the previously obtained information about variable parameters, optimization criteria and constraints), as well as active, when the set is generated in the initial search field in accordance with the preset partition law. Each vector of variable parameters for optimization and constraints implies direct use of mathematical model of the object studied. The number of points in the initial experiment plan depends on the problem dimension and the chosen variant of approximation function.

\section{Results and discussion}

To find the minimum mass of the ribs of the heat-exchange apparatus with the maximum of its heat productivity developed mathematical model of multi-criteria optimization problem parameters heat-giving elements of the heat-exchange apparatus systems of air heating of buildings, which is solved using the method of nonlinear optimization [1]. Formulation of the mathematical model has been made for the outer surface of the radial ribs (Fig. 1). The temperature on the surface of the ribs defines heat output, and the height of the rib - metal heat-exchange apparatus, so as the optimality criteria for staging a mathematical model selected [2]:1) the temperature on the surface of the ribs (J1);2) the height of the ribs (J2). 


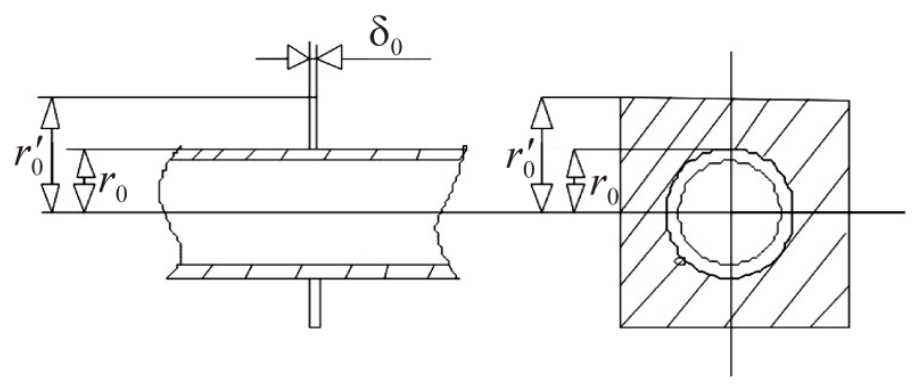

Fig. 1. Radial ribs.

As unmanaged parameters taken: the radius of the carrier pipe, of a thickness of edges, the thermal conductivity of the ribs, the location of the beam in a heat exchanger, step ribs, the number of ribs, the number of the Nusselt number for the air, the Reynolds number for the air, the coefficient of heat transfer from the wall to the air, etc. $\left(x_{1} \ldots x_{21}\right)$.

In work the estimation of influence of these parameters on the process of heat exchanger.

As of controlled parameters are: ambient air temperature, the temperature of the heat-carrier $\left(\mathrm{U}_{1} \ldots \mathrm{U}_{2}\right)$ as the most influence on the heat transfer process.

In the process of heat exchange occurs between the warm water and the environment, which depend on parameters of water and air. Parameters that characterize these changes are within the permissible limits, established for the process.

The dependence of optimization criteria [3] and process parameters:

$$
\begin{aligned}
& J_{1}=J_{1}\left(x_{1}, \ldots x_{21} ; U_{1}, U_{2}\right) \rightarrow \max \\
& J_{2}=J_{2}\left(x_{1}, \ldots x_{21} ; U_{1}, U_{2}\right) \rightarrow \min .
\end{aligned}
$$

Restrictions on the parameters of the process, is within the following limits:

$$
\begin{gathered}
x_{i}^{\min } \leq x \leq x_{i}^{\max }, \\
J_{i}^{\min } \leq J_{i}\left(x_{i}\right) \leq J_{i}^{\max } \\
r=r_{0} ; \vartheta=\vartheta_{0} ; r=r_{0}^{\prime} ; \frac{d \vartheta}{d r}, \delta_{0}, \lambda_{c_{2}}=\text { const. }
\end{gathered}
$$

The task of searching for the optimal height of the ribs is to find $\mathrm{x} \in \mathrm{D}$ in cases, when

$$
\begin{aligned}
& J_{1}\left(x_{1}, \ldots x_{21}, U_{1}, U_{2}\right) \rightarrow \max , \\
& J_{2}\left(x_{1}, \ldots x_{21}, U_{1}, U_{2}\right) \rightarrow \min .
\end{aligned}
$$

Thus, the problem can be formulated as follows: it is required to find such controlled parameters of the element heat exchanger (fins), which are optimal from the perspective of the selected criteria under the given constraints.

The basis of mathematical model equations Bessel, describing the temperature distribution on the outer surface of the ribs.

Modified Bessel equation for the radial fin of rectangular profile is:

$$
r^{2} \frac{d^{2} \vartheta}{d r^{2}}+r \frac{d \vartheta}{d r}-m^{2} r^{2} \vartheta=0
$$




$$
m=\frac{2 \alpha}{\lambda_{c_{2}} \delta}
$$

where, $m$ - the dimensionless complex; $\alpha$ - heat transfer coefficient from the outer surface to the air, Watt $/\left(\mathrm{m}^{2} *\right.$ degrees $) ; \lambda_{c_{2}}-$ thermal conductivity of fin, Watt/(m* degrees $) ; \delta-$ thickness of fin, $m$.

The heat transfer coefficient from the outer surface to the air, Watt $/\left(\mathrm{m}^{2} * \operatorname{grad}.\right)$ :

$$
\alpha=\frac{\mathrm{Nu}_{\mathrm{B}} \cdot v_{\mathrm{B}}}{h},
$$

where $\mathrm{Nu}_{\mathrm{B}}-$ is the Nusselt number for air; $v_{\mathrm{B}}-$ coefficient of kinematic viscosity of air, $\mathrm{m}^{2} / \mathrm{s} ; \mathrm{h}$ - fin height, $\mathrm{m}$.

The Nusselt number for turbulent regime of the air movement:

$$
\mathrm{Nu}_{\mathrm{B}}=0,096 \cdot \operatorname{Re}_{\mathrm{B}}^{0,72} \cdot\left(\frac{d_{\mathrm{H}}}{h_{\mathrm{p}}}\right)^{0,54} \cdot\left(\frac{h}{h_{\mathrm{p}}}\right)^{-0,14},
$$

where $\mathrm{R}$ - step rib, $\mathrm{m}$; $\mathrm{d}$ - outside diameter of pipe, $\mathrm{m}$; $\mathrm{h}$ - height of fin, $\mathrm{m} ; \mathrm{Re}_{\mathrm{B}}-$ Reynolds number for air.

Given the heat transfer coefficient:

$$
\alpha_{2 \text { пр }}=\alpha_{2} \cdot\left(\frac{F_{\mathrm{p}} \cdot \theta_{0}}{F_{p c} \cdot \theta_{1}}+\frac{F_{\text {п }}}{F_{p c}}\right),
$$

where $\alpha_{2}$ - heat transfer coefficient, Watt/( $\mathrm{m}^{2} *$ degrees $) ; \theta_{0}$ - is the difference between the temperatures of the surfaces of the ribs and of air, degrees; $\theta_{1}-$ the difference in temperature between the core tube surface and air, degrees; $F_{\Pi}$ - surface area between the ribs, $\mathrm{m}^{2} ; F_{p c}-$ area finned surface, $\mathrm{m}^{2} ; F_{\mathrm{p}}-$ area of fins, $\mathrm{m}^{2}$.

The General solution is determined by the ratio:

$$
\theta=C_{1} J_{0}(m r)+C_{2} K_{0}(m r)
$$

The constant $K_{1}, K_{0}, J_{0}, J_{1}$ is calculated in accordance with boundary conditions described above:

$$
\begin{aligned}
& \theta_{0}=C_{1} J_{0}\left(m r_{0}\right)+C_{2} K_{0}\left(m r_{0}^{\prime}\right), \\
& 0=C_{1} J_{1}\left(m r_{0}\right)+C_{2} K_{1}\left(m r_{0}\right) .
\end{aligned}
$$

Calculating $C_{1}, C_{2}$ we find the temperature distribution along fin height for the radial fin of rectangular shape (grad.):

$$
\theta(r)=\frac{\theta_{0}\left(\left(K_{1}\left(m r_{0}^{\prime}\right) \cdot J_{0}(m r)+J_{1}\left(m r_{0}^{\prime}\right) K_{0}(m r)\right)\right.}{J_{0}\left(m r_{0}\right) K_{1}\left(m r_{0}^{\prime}\right)+J_{1}\left(m r_{0}^{\prime}\right) K_{0}\left(m r_{0}\right)},
$$

where $\theta_{0}$ is the temperature on the surface of the carrier pipe, degrees. 
To estimate the heat flux from the surface of the ribs used in the work the dependence proposed by Bessel:

$$
q_{0}=2 \pi_{0} r \delta_{0} \lambda m \theta_{0}\left[\frac{J_{1}\left(m r_{0}^{\prime}\right) K_{1}\left(m r_{0}\right)-K_{1}\left(m r_{0}^{\prime}\right) J_{1}\left(m r_{0}\right)}{J_{0}\left(m r_{0}\right) K_{1}\left(m r_{0}^{\prime}\right)+J_{1}\left(m r_{0}^{\prime}\right) K_{0}\left(m r_{0}\right)}\right] .
$$

Thus, the problem can be formulated in the following way: it is required to find such managed parameters element of heat exchanger (the height of the edges), which are optimal from the point of view you are the chosen criteria under certain constraints.

The basis of mathematical model based on Bessel equation describing the distribution of temperature on the outer surface of the ribs [4].

For the staging of the mathematical model are determined boundary conditions of the process of heat transfer in the work of the air heating systems, described in the dependencies $(2,3,4)$.

To create the most resource-efficient heat exchangers in the article the low temperature and middle temperature of the heating system of the buildings with the following parameters the heat-carrier from +45 to +95 degrees. With these parameters the heat exchanger of the most metal-consuming.

To identify the most critical conditions of heat exchange on the surface of the ribs considered by the turbulent mode of movement of the heat-carrier temperature of ambient air from -35 up to 10 degrees. The analysis of use of brands fans in systems of air heating of buildings. Set the maximum speed of the air entering the heat exchanger $-7 \mathrm{~kg} /\left(\mathrm{m}^{2}\right.$ • degrees), which would consider in selecting the data of heat exchangers. Solution of the task is carried out with the help of the method of conjugate gradients - iterative method for unconstrained optimization of the multidimensional space, of the solution of a quadratic optimization problem for a finite number of steps.

As a software complex for solving multi-parameter nonlinear multi objective optimization of engineering systems of buildings used IOSO NM [7].

A feature of this complex is compatible with Microsoft Excel and other programs. Empirically obtained data are compiled in Excel. In the program IOSO are controllable and uncontrollable parameters, optimality criteria, restrictions on the parameters of the process. Next, the program IOSO generates optimal process parameters selection method from Excel [8].

Preliminary procedure IOSO is the formation of the initial experiment plan that could be implemented as a passive way (using information about various parameters, the optimization criteria and constraints obtained earlier) and active way, when too much is generated in the initial search area in accordance with a given distribution law. For each vector of variable parameters, the values of the optimization criteria and constraints are determined by direct appeal to the mathematical model of the investigated object. The number of points constituting the initial plan of the experiment depends on the dimension of the problem and the selected approximation functions.

In Fig. 2 shows the Pareto-optimal set of values when solving multi-criteria parameter optimization of a fin heat exchanger by using design software IOSO NM obtained the optimal values. For ease of understanding the obtained values of the graphs for each controlled parameter. 
The temperature,

degrees

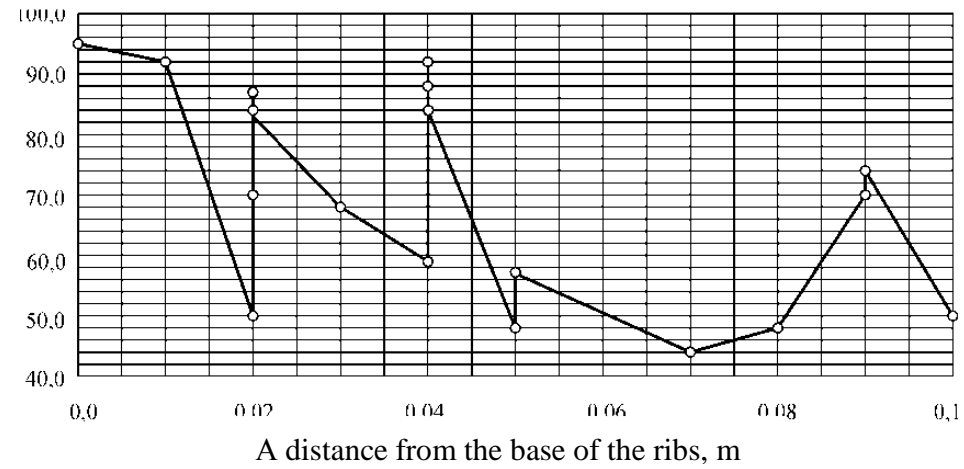

Fig. 2. The temperature of the substrate surface (degrees) from a distance from the base of the ribs (m), (the optimal solution).

\section{Conclusion}

Improving the energy efficiency of engineering systems of buildings and structures, reduction of energy consumption through the optimization of their operation, introduction of energy saving technologies and optimization of structural elements of engineering systems is important.

As applied problems of improvement of engineering systems of buildings considered an example of optimization of heat exchanger element air heating system of the building.

Finding the best managed of the parameters of the heat exchanger element air heating system of a building is possible with the developed by the author of a comprehensive method of research based on multi-criteria parameter optimization with the introduction of empirically obtained data. When developing a mathematical model of the heat exchanger element air heating system of a building used for the basic equations of heat and mass transfer. The decision of tasks of optimization carried out using the method of nonlinear optimization in design-software complexes IOZO.

\section{References}

1. Melekhin A.A., Melekhin A.G. Optimization of parameters of heat exchangers of air heating systems; Applied Mechanics and Materials, vol.672-674, p.1471-1480; Switzerland; 1662-7482, (2014)

2. A. S. Lapidus. Selection of criteria for the engineering and economical optimization of heat exchangers. International Journal of Chemical and Petroleum Engineering. Publisher: Springer New York. February, Volume 13, Issue 2. P 160-165. (1977)

3. I.M. Sobol, R.B. Statnikov. The choice of optimal parameters in problems with many criteria. (Moscow: Science, 1981)

4. B.M. Khrustalev, A.P. Nesenchuk. Heat and mass transfer. 1 part. (Minsk: Belarusian national technical University, 2007)

5. EU. The Vilkas, AS Maiminas. Solution: theory, information, modeling. (Moscow: Radio and communication, 1981)

6. D. Himmelblau. Applied nonlinear programming. Translation from English publishing house "World", Moscow. (1975) 
7. Egorov I.N., Kretinin G.V., Leschenko I.A., Kuptcov S.V. "Multi-objective Optimization Using IOSO Technology", 7-th ASMO UK / ISSMO Conference on engineering Design optimization, Bath, UK, 7-8 July (2008)

8. Mohammad Reza Salimpour, Zabihollah Bahrami. Thermodynamic analysis and optimization of air-cooled heat exchangers. International Journal of Heat Mass Transfer. Publisher: Springer New York. January 2011. Volume 47. Issue 1. P 35-44, (2011)

9. The tool Microsoft Excel solver uses an algorithm of nonlinear optimization Generalized Reduced Gradient (GRG2), developed by the Leon Lasdon (University of Texas at Austin) and Allan Waren (Cleveland State University).

10. Burke E.K., Landa Silva J.D., Soubeiga E. Hyperheuristic Approaches for Multiobjective Optimization. Proceeding of the MIC 2003, Kyoto Japan, (2003)

11. S. Liu and M. Saker, "A comprehensive review on passive heat transfer enhancements in pipe exchangers," Renewable and Sustainable Energy Reviews, vol. 19, pp. 64-81 (2013)

12. M. I. Hasan, A. M. A. Rageb, and M. Yaghoubi, "Investigation of a counter flow microchannel heat exchanger performance with using nanofluid as a coolant," Journal of Electronics Cooling and Thermal Control, vol. 2, no. 2, pp. 35-43, (2012)

13. A. Bejan, Convection Heat Transfer, John Wiley \& Sons, New York, NY, USA, 4th edition, (2013) 